\title{
Barium ferrite/epoxy resin nanocomposite system: Fabrication, dielectric, magnetic and hydration studies
}

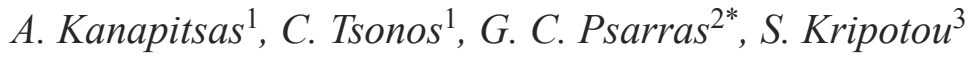 \\ ${ }^{1}$ Electronics Engineering Department, Technological Educational Institute of Sterea Ellada, 35100 Lamia, Greece \\ ${ }^{2}$ Department of Materials Science, School of Natural Sciences, University of Patras, 26504 Patras, Greece \\ ${ }^{3}$ Department of Physics, School of Applied Mathematical and Physical Sciences, National Technical University of Athens, \\ Zografou 15780, Athens, Greece
}

Received 23 July 2015; accepted in revised form 5 October 2015

\begin{abstract}
Composite systems of epoxy resin and barium ferrite nanoparticles have been prepared, and studied varying the content of the inclusions. Morphology of prepared samples has been examined via scanning electron microscopy and X-ray diffraction spectra, while electrical and magnetic properties were investigated by means of broadband dielectric spectroscopy, and magnetization tests respectively. Finally, water vapor sorption measurements were conducted in order to study the water sorption dynamics of the system. Electron microscopy images revealed the successful fabrication of nanocomposites. Dielectric permittivity increases with filler content, while three relaxation processes were detected in the relative spectra. These processes are attributed to interfacial polarization, glass to rubber transition of the matrix, and re-orientation of polar side groups of the polymer's chain. Magnetization and magnetic saturation increase with magnetic nano-powder content. Nanocomposites absorb a small amount of water, not exceeding $1.7 \mathrm{wt} \%$, regardless filler content, indicating their hydrophobic character.
\end{abstract}

Keywords: nanocomposites, barium ferrite, dielectric properties, magnetic properties, hydration

\section{Introduction}

M-type barium ferrite with hexagonal structure $\left(\mathrm{BaFe}_{12} \mathrm{O}_{19}\right)$ is a well-known high-performance permanent magnetic material, owing to its high magnetocrystalline anisotropy, high Curie temperature, relatively large magnetization, excellent chemical stability and corrosion resistance. M-type hexaferrites have continuously made inroads in applications such as plastoferrites, injection-molded pieces, microwave devices, and magnetic recording media. With proper design and substitutions, passive elements including mm-wave circulators can be constructed from hexaferrites. Ba-hexaferrites with composition of $\mathrm{BaFe}_{12} \mathrm{O}_{19}$, are the most widely used among the various hexaferrite compounds. The most significant property is the very high mag- netocrystalline anisotropy field $(1.7 \mathrm{~T})$, which results in a high coercivity, remanence and a ferromagnetic resonance at around $50 \mathrm{GHz}$, [1]. Recently increased attention is given to ferrites, ferrite based complex ceramics, and to magnetic semiconductors [2-8]. The majority of these works refers to the variation of magnetic permeability, dielectric permittivity at $\mathrm{GHz}$, and absorption properties, with the composition and the preparation procedure of ceramic compounds. On the other hand studies concerning the magnetic behaviour of polymer based composites are still scarce [9-13].

Polymers exhibit a number of advantages, which include ease processing and forming, thermomechanical stability, high dielectric breakdown strength and low cost. Conductivity, dielectric and magnetic

\footnotetext{
${ }^{*}$ Corresponding author, e-mail: G.C.Psarras@upatras.gr

(C) BME-PT
} 
properties of polymers can be substantially altered by embedding suitable reinforcing inclusions. Dielectric and magnetic response can be tuned by controlling the amount and the type of the employed ceramic inclusions [14-17]. Epoxy resins are extensively used for the production of high tech composites in the fields of automotive, aerospace and electronic industries, mostly due to their high stiffness and good adhesion with the inclusions [18-21]. However, a possible drawback in micro or nano epoxy composites' performance could be related to the effect of environmental attack and the resulting degradation. Water uptake due to the exposure in humid environments is a major factor influencing performance and service life of composites.

In this work nanocomposites constituted of an epoxy resin matrix and barium ferrite nanoparticles as the reinforcing phase, have been prepared and studied, at various filler content. It is a first attempt to fabricate a single-filler nanocomposite system with tunable magneto-electric response, suitable for outdoors applications. Specimens' morphology was assessed via scanning electron microscopy (SEM) and X-ray diffraction (XRD) spectra, while dielectric and magnetic response were studied by means of broadband dielectric spectroscopy (BDS) and magnetization measurements, respectively. Finally, hydration studies were performed by water vapor sorption measurements.

\section{Experimental}

\subsection{Materials and nanocomposites manufacturing}

Nanocomposite specimens were prepared by employing commercially available materials. In particular a low viscosity epoxy resin (ER) (Epoxol 2004A) was used as a prepolymer, while Epoxol 2004B (operating at a slow rate) was used as curing agent. Both reactants were supplied by Neotex S.A., Athens, Greece. Barium ferrite $(\mathrm{BaFe})$ particles were purchased by Sigma-Aldrich. The mean particle diameter was less than $100 \mathrm{~nm}$. The preparation procedure involved mixing of the resin with the curing agent in a 2:1 (w/w) ratio and then adding, while the polymer system was still in the liquid state, various amounts of the filler. Stirring at a low rate, degassing the mixtures in a vacuum-oven, and ultrasonication were also included in the preparation procedure [21, 22]. The content of barium ferrite in the produced specimens was $0,3,10,20,30$, and 50 parts per hundred resin $[\mathrm{phr}]$. Filler's content and respective volume fractions are listed in Table 1. The initial curing took place at ambient for a week, followed by post-curing at $100^{\circ} \mathrm{C}$ for 4 hours. The specimens' morphology, as well as, the achieved quality of the filler dispersion within the polymer matrix was examined via Scanning Electron Microscopy (SEM) (EVO MA 10, ZEISS). X-ray diffraction analyses were made by Siemens diffractometer model Z500, by using $\mathrm{Cu}-\mathrm{Ka}(\lambda=1.54056 \AA, 40 \mathrm{kV}, 30 \mathrm{~mA})$ in wide range of Braggs angles $20-90^{\circ}$.

\subsection{Dielectric and magnetic measurements}

Dielectric measurements were conducted by means of broadband dielectric spectroscopy (BDS) using an Alpha-N Frequency Response Analyser, supplied by Novocontrol Technologies (Hundsagen, Germany). The applied Vrms was kept constant at $1000 \mathrm{mV}$, while field's frequency was varied between $10^{-1}$ to $10^{6} \mathrm{~Hz}$. Isothermal scans were carried out in the temperature range from ambient to $150^{\circ} \mathrm{C}$, in steps of $5^{\circ} \mathrm{C}$. Temperature was controlled via the Novotherm system within $\pm 0.1^{\circ} \mathrm{C}$ (Novocontrol Technologies). The employed dielectric test cell was the BDS-1200, parallel-plate capacitor with two gold-plated electrodes system, supplied also by

Table 1 Barium ferrite content in phr and volume fraction in the examined specimens, magnetic saturation and remanence magnetization of nanocompsoites and neat barium ferrite

\begin{tabular}{|l|c|c|c|}
\hline \multicolumn{1}{|c|}{ Specimen } & $\begin{array}{c}\text { Volume fraction } \\
{[\mathbf{\%}]}\end{array}$ & $\begin{array}{c}\text { Magnetic saturation: } \boldsymbol{M}_{\mathbf{s}} \\
{[\mathbf{e m u} / \mathbf{g}]}\end{array}$ & $\begin{array}{c}\text { Remanence magnetization } \\
\text { [emu/gr] }\end{array}$ \\
\hline Epoxy resin & 0 & - & - \\
\hline Epoxy resin $+3 \mathrm{phr} \mathrm{BaFe}_{12} \mathrm{O}_{19}$ & 0.60 & 0.25 & 0.08 \\
\hline Epoxy resin $+10 \mathrm{phr} \mathrm{BaFe}_{12} \mathrm{O}_{19}$ & 1.98 & 0.50 & 0.15 \\
\hline Epoxy resin $+20 \mathrm{phr} \mathrm{BaFe}_{12} \mathrm{O}_{19}$ & 3.79 & 1.59 & 0.50 \\
\hline Epoxy resin $+30 \mathrm{phr} \mathrm{BaFe}_{12} \mathrm{O}_{19}$ & 5.69 & 1.85 & 0.56 \\
\hline${\text { Epoxy resin }+50 \mathrm{phr} \mathrm{BaFe}_{12} \mathrm{O}_{19}}_{\mathrm{BaFe}_{12} \mathrm{O}_{19}}$ & 8.80 & 3.16 & 0.95 \\
\hline
\end{tabular}


Novocontrol Technologies. The dielectric cell was electrically shielded and data acquisition was fully automated and conducted via suitable software.

The magnetization measurements were performed using a Quantum Design superconducting quantum interference device (SQUID), with maximum field at 5 Tesla. The hysteresis loops were measured up to $5 \mathrm{~T}$. The zero-field-cooled (ZFC) and field cooled (FC) processes were recorded at low magnetic fields in temperature range from 5 to $300 \mathrm{~K}(-268.2$ to $26.8^{\circ} \mathrm{C}$ ). Before each run, samples were demagnetized at $300 \mathrm{~K}\left(26.8^{\circ} \mathrm{C}\right)$ by applying an oscillatory magnetic field, and then cooled down in zero fields to $5 \mathrm{~K}\left(-268.2{ }^{\circ} \mathrm{C}\right)$. At $5 \mathrm{~K}\left(-268.2^{\circ} \mathrm{C}\right)$, a small magnetic field of the order of 100 or 1000 Oe in the powder was applied, and the magnetization was measured as we heated the sample to $300 \mathrm{~K}$ $\left(26.8^{\circ} \mathrm{C}\right)$. This procedure was denoted as the ZFC measurement. At $300 \mathrm{~K}$, the small-applied magnetic field was kept as it is and then samples were cooled again to $2 \mathrm{~K}\left(-271.2{ }^{\circ} \mathrm{C}\right)$, with a subsequent recording of the magnetization as we heated the sample to $300 \mathrm{~K}\left(26.8^{\circ} \mathrm{C}\right)$. Such measurement was denoted as $\mathrm{FC}$ measurement.

\subsection{Hydration studies}

Water vapor sorption measurements were performed using VTI SA+ vapor sorption analyzer supplied by TA Instruments. The sample mass was continuously recorded as a function of time, until equilibrium was reached, at different levels of relative humidity between 10 and $95 \%$ both while increasing (sorption) and decreasing (desorption). All the measurements were done at a constant temperature of $25^{\circ} \mathrm{C}$.

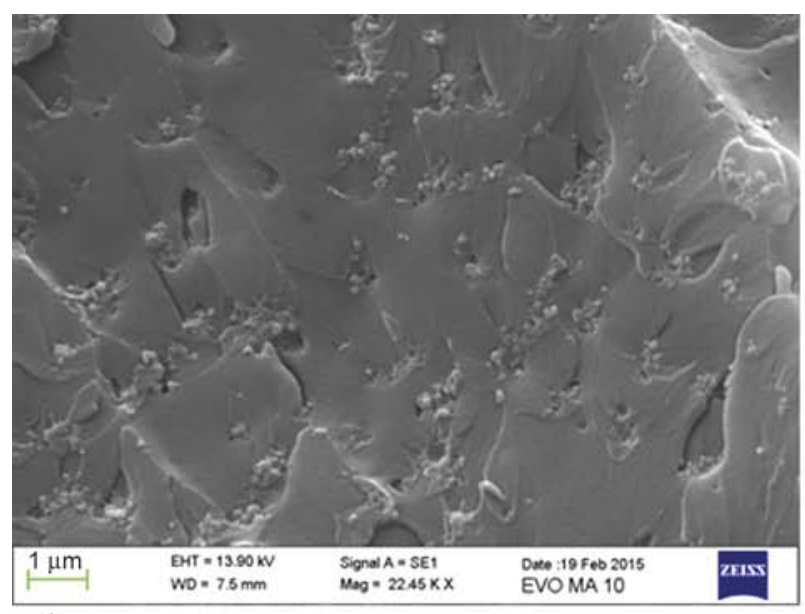

a)

\section{Results and discussion}

Figure 1 depicts representative SEM images of the fracture surface of the nanocomposites with 3 (Figure 1a) and $5 \mathrm{phr}$ (Figure 1b) in barium ferrite content. In all examined cases nanodispersions were detected in tandem with small clusters, denoting the successful manufacturing of the $\mathrm{BaFe}_{12} \mathrm{O}_{19} /$ epoxy resin nanocomposites. In the literature there are many studies [23-27], especially for $\mathrm{BaTiO}_{3}$ reinforced polymer nanocomposites, where surface modifications of filler's particles result in better distribution of nanoinclusions. Although, this is the general trend and surface modification is considered as beneficial to both nanodispersions and physical properties, filler's modification should not be considered as a panacea. Surface modification could add a type of coating to nanoinclusions with different electrical properties, being detrimental sometimes to the desired electrical behaviour of the nanocomposites $[24,28,29]$.

XRD spectra of barium ferrite nanopowder and the nanocomposite with $3 \mathrm{phr}$ magnetic powder are shown in Figure $2 a$ and $2 b$, respectively. XRD data revealed the presence of $\mathrm{Fe}_{2} \mathrm{O}_{3}$ within the magnetic powder. Moreover, grain diameters calculated using the Sherrer formula of $28 \mathrm{~nm}$ for $\mathrm{BaFe}_{12} \mathrm{O}_{19}$ and $26 \mathrm{~nm}$ for $\mathrm{Fe}_{2} \mathrm{O}_{3}$, were found. An analogous picture is obtained for the $3 \mathrm{phr} \mathrm{BaFe}_{12} \mathrm{O}_{19}$ /epoxy resin nanocomposite.

Dielectric spectra of the ER/20 phr $\mathrm{BaFe}_{12} \mathrm{O}_{19}$ are shown in the 3D graphs of Figure 3. Variation of the real part of dielectric permittivity $\left(\varepsilon^{\prime}\right)$ as a function of frequency and temperature is presented in Figure 3a. Permittivity increases with diminishing of

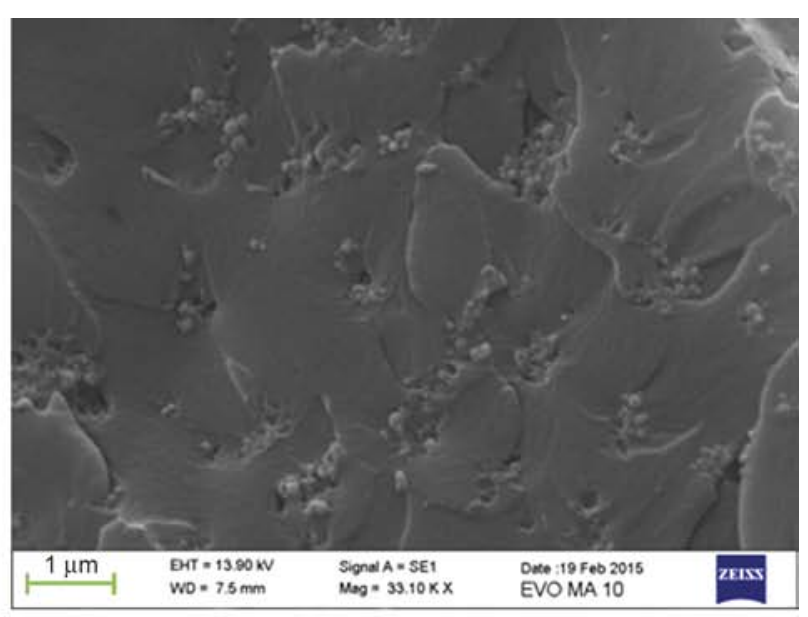

b)

Figure 1. SEM images from the specimens with (a) 3 and (b) 5 phr barium ferrite content 

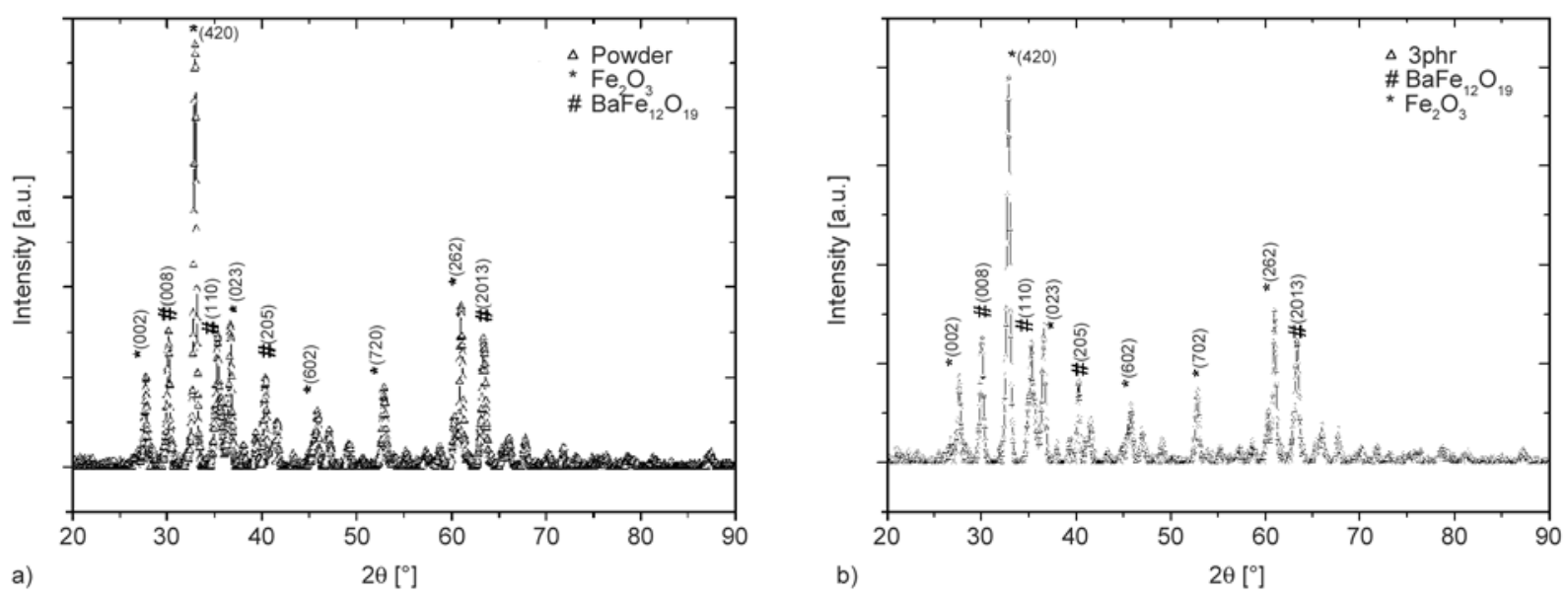

Figure 2. XRD spectra of (a) barium ferrite nanopowder, and (b) the composite with 3 phr barium ferrite

frequency, since dipoles attain sufficient time to orient themselves in the direction of the alternating field. Temperature facilitates this process by supplying thermal agitation to dipoles, and thus $\varepsilon^{\prime}$ acquires high values in the low frequency and high temperature ranges. Two step-like transitions, recorded in the permittivity's spectra, indicate the presence of dielectric relaxation processes. Relaxation processes became evident in the loss tangent versus frequency and temperature spectra of Figure 3b, by the formation of loss peaks. Three distinct processes can be observed in Figure 3b. The slower process, recorded in the low frequency and high temperature region, characterized by the longer relaxation time, is attributed to Interfacial Polarization (IP). IP occurs in heterogeneous systems, because of the accumulation of unbounded charges at the interface of the constituents [22, 30, 31]. These charges form dipoles at the system's interface, which are forced to follow the alternation of the applied field. Their inertia to be aligned parallel to the field is responsible for the relaxation process, and enhanced polarization is achieved only at a low alternation rate of the field and when adequate amount of thermal energy is provided. In the intermediate zone of Figure $3 b$, another relaxation mechanism is present. Its physical origin is related to the simultaneous segmental motion of large parts of the macromolecular chains, due to the glass to rubber transition of the amorphous polymer matrix. This process, denoted as $\alpha$ relaxation, corresponds to a shorter relaxation time compared to IP. It should be noted that glass transition temperature $\left(T_{\mathrm{g}}\right)$ of the employed epoxy resin, as determined via differential scanning calorimetry (DSC) studies in a previous work of ours [22], is very close to $60^{\circ} \mathrm{C}$. Above $T_{\mathrm{g}}$, besides the synergetic motion of macromolecules, the difference of the coefficients of thermal expansion between matrix
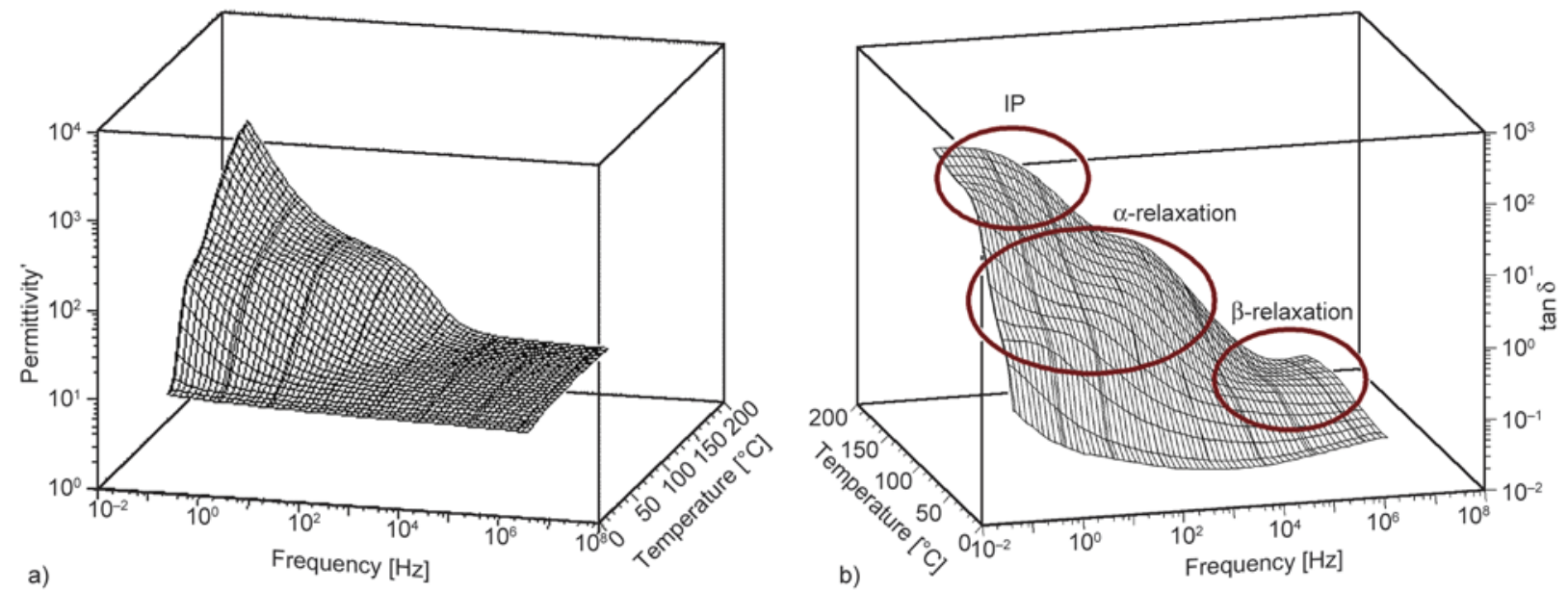

Figure 3. (a) Real part of dielectric permittivity, and (b) loss tangent as a function of frequency and temperature, for the composite with $20 \mathrm{phr}$ barium ferrite 

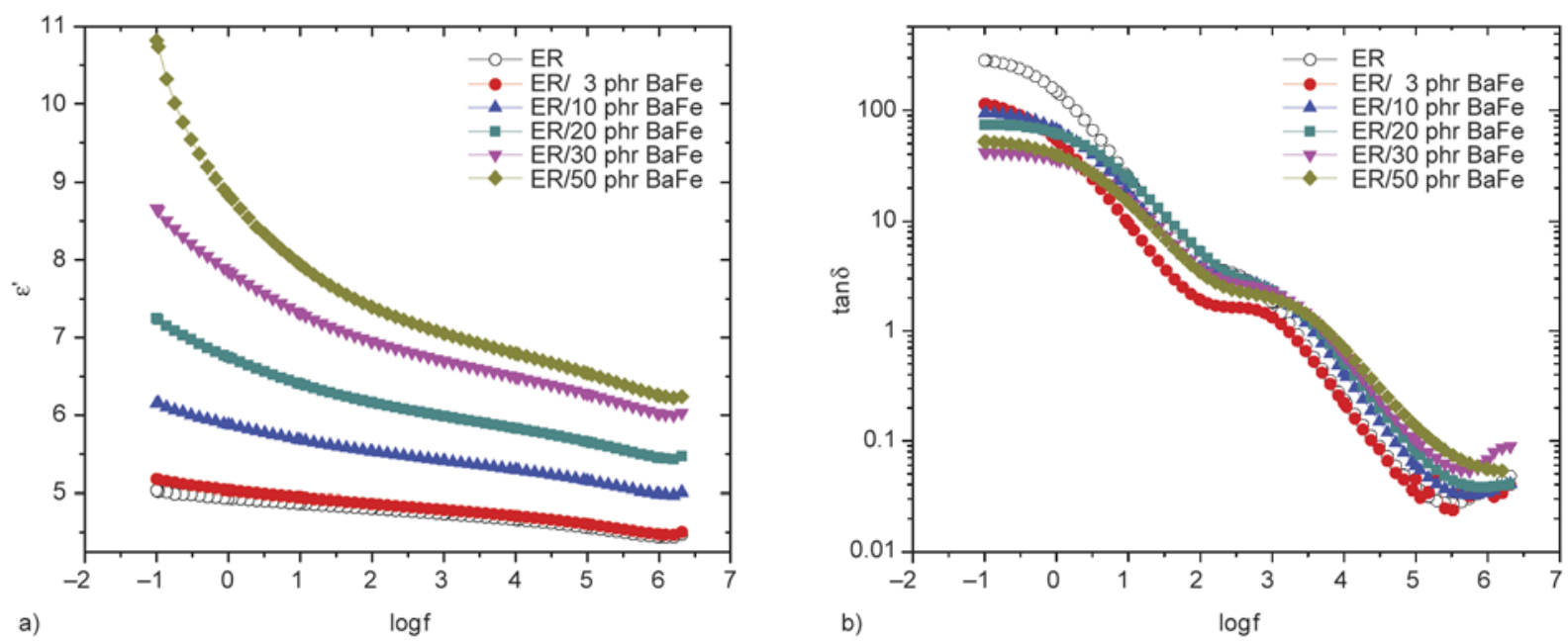

Figure 4. (a) Real part of dielectric permittivity, and (b) loss tangent vs frequency for all tested systems at 30 and $160{ }^{\circ} \mathrm{C}$ respectively

and filler could affect the dielectric response of the nanocomposites by the possible disruption of the particle/polymer contacts. The third process, occurring in the low temperature and high frequency region, is a relative weak mechanism ascribed to the re-orientation of polar side groups of the main polymer chains ( $\beta$-relaxation) [22].

Figure $4 \mathrm{a}$ displays comparative plots of the real part of dielectric permittivity $\left(\varepsilon^{\prime}\right)$, as a function of frequency, for all the examined specimens, at $30^{\circ} \mathrm{C}$. As expected, $\varepsilon^{\prime}$ increases with filler content in the whole frequency range, since barium ferrite nanoparticles exhibit higher values of permittivity than the polymer matrix. This increase is more pronounced in the low frequency region, because system's heterogeneity increases with barium ferrite content, leading thus to enhanced IP effect. Comparative plots of the loss tangent ( $\tan \delta$ ), as a function of frequency, for all the examined specimens, at $160^{\circ} \mathrm{C}$, are shown in Figure 4b. The previously mentioned relaxations are present in these loss spectra. Interestingly, IP is observed in the neat epoxy spectrum, and loss index attains high values. IP has been detected in loss spectra of many polymers due to the presence of additives, impurities and plasticizers [32-35]. On the other hand, increased values of loss tangent should be related to high values of the dielectric loss $\left(\varepsilon^{\prime \prime}\right)$, since tan $\delta$ is defined as the ratio of the imaginary to the real part of dielectric permittivity. High values of $\varepsilon^{\prime \prime}$ in the low frequency region and at high temperatures are related to: (i) enhanced conductivity, (ii) IP, (iii) electrode polarization, or to any combination of these three effects. The low conductivity and low heterogeneity of the employed ther- mosetting resin implies electrode polarization, as the main reason for the high values of $\varepsilon^{\prime \prime}$, and thus of $\tan \delta$. Considering that the type of electrodes/ specimens contact in all cases is the same, it is reasonable to suggest that the contribution of electrode polarization in the recorded values of dielectric loss remains constant. Under this point of view, and recalling the low values of conductivity for the examined systems, variations of dielectric loss and $\tan \delta$ with filler content should be related to interfacial polarization phenomena. Thus, in the case of nanocomposites, values of $\tan \delta$ appear to diminish with barium ferrite content, reflecting the increase of $\varepsilon^{\prime}$ due to the enhanced heterogeneity, and denoting IP as the dominating effect.

Magnetization hysteresis curves for barium ferrite nanopowder and $\mathrm{BaFe}_{12} \mathrm{O}_{19}$ /epoxy nanocomposites are depicted in Figure 5a and 5b, respectively. Neat barium ferrite exhibits the highest values of magnetization and coercivity, Figure 5a. Additional nanocomposites' magnetization and coercivity increase systematically with filler content, as expected, Figure $5 b$.

Figures $5 \mathrm{a}$ and $5 \mathrm{~b}$ show the magnetic hysteresis loops (M-H) of $\mathrm{BaFe}_{12} \mathrm{O}_{19}$ nanopowder and nanocomposites, respectively. Neat barium ferrite exhibits the highest values of magnetization. $\mathrm{M}-\mathrm{H}$ curve of pure $\mathrm{BaFe}_{12} \mathrm{O}_{19}$ nanopowder shows a ferromagnetic hysteresis loop with magnetic saturation $\left(M_{\mathrm{s}}\right)$ $14 \mathrm{emu} / \mathrm{g}$, magnetic remanence $\left(M_{\mathrm{r}}\right) 4.09 \mathrm{emu} / \mathrm{g}$ and coercive field $\left(H_{\mathrm{c}}\right) 1.3 \mathrm{kOe}$. The coercive field is significantly lower from the nominal value of $\mathrm{BaFe}_{12} \mathrm{O}_{19}$. The reason is that the $\mathrm{BaFe}_{12} \mathrm{O}_{19}$ nanoparticles, interacts with oxygen and a new phase $\mathrm{Fe}_{2} \mathrm{O}_{3}$ is formed 

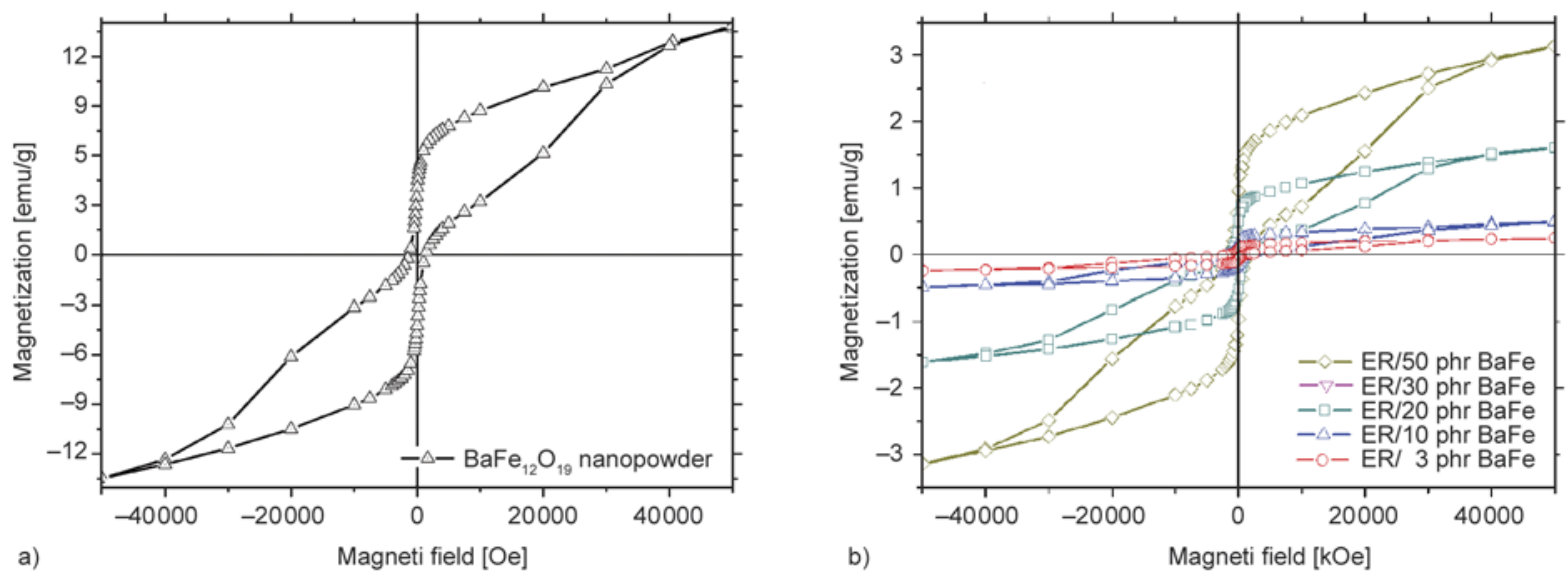

Figure 5. Magnetic hysteresis loops of (a) barium ferrite nanopowder, and (b) nanocomposites with different content of barium ferrite

and coexists with $\mathrm{BaFe}_{12} \mathrm{O}_{19}$ phase. The coercive field as an intrinsic property of the $\mathrm{BaFe}_{12} \mathrm{O}_{19}$ nanoparticles remains constant at nanocomposites with the same value of $1.3 \mathrm{kOe}$.

Increasing the magnetic nanoparticles' content, results in enhanced values of saturation and remanence magnetization in the nanocomposites. Obtained values of magnetic saturation and remanence magnetization are listed in Table 1. Barium ferrite nanoparticles induce magnetic properties to polymer matrix, and thus is quite reasonable the increase of magnetization, magnetic saturation and remanence magnetization of nanocomposites with magnetic phase content.

Figure 6 shows the water vapor sorption measurement for the nanocomposite with $10 \mathrm{phr} \mathrm{BaFe}_{12} \mathrm{O}_{19}$, as a typical example. From the equilibrium mass at each relative humidity the sorption isotherm (equilibrium water content calculated in dry mass basis

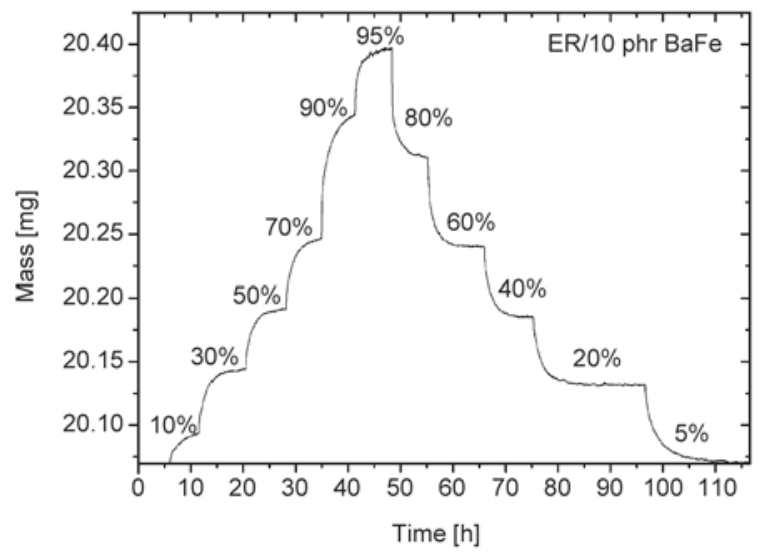

Figure 6. Typical water vapor sorption measurement. Mass as a function of time at $25^{\circ} \mathrm{C}$ at different levels of relative humidity during sorption and desorption for the nanocomposite with $10 \mathrm{phr} \mathrm{BaFe}_{12} \mathrm{O}_{19}$. as a function of water activity (relative humidity/100)) can be constructed. The sorption isotherm for the nanocomposite with $10 \mathrm{phr} \mathrm{BaFe}_{12} \mathrm{O}_{19}$ is shown in Figure 7. Data obtained during desorption are also included in the graph. The sorption isotherm is of Type II in the Brunauer classification [36], which describes adsorption on macroporous adsorbents with strong adsorbate-adsorbent interactions. The percentage of water content at the highest water activity was found close to $1.7 \mathrm{wt} \%$ indicating the hydrophobic character of the sample, while no significant hysteresis was found indicating that the adsorbed water do not cause permanent changes in the sample.

Experimental data were fitted by GuggenheimAnderson-de Boer (GAB) equation (Equation (1)):

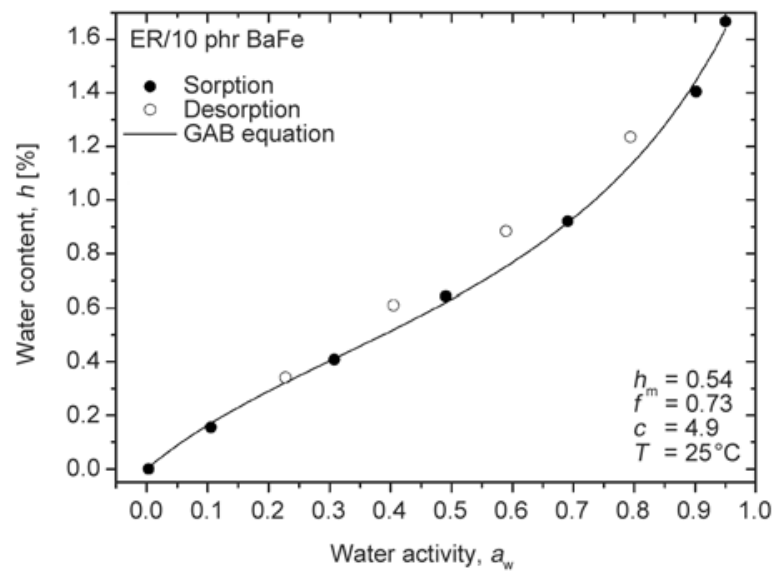

Figure 7. Sorption isotherm for the nanocomposite with $10 \mathrm{phr} \mathrm{BaFe}_{12} \mathrm{O}_{19}$ at $25^{\circ} \mathrm{C}$. Data during desorption (open symbols) are also included. The line is the best fit of GAB equation to the experimental data. The values of GAB parameters are indicated on the plot. 


$$
h\left(a_{\mathrm{w}}\right)=h_{\mathrm{m}} \cdot \frac{c \cdot f \cdot a_{\mathrm{w}}}{\left(1-f \cdot a_{\mathrm{w}}\right)\left[1+(c-1) f \cdot a_{\mathrm{w}}\right]}
$$

where $h$ is the percentage of water content calculated in dry mass basis $h=\left[\left(m_{\text {equil }}-m_{\text {dry }}\right) / m_{\text {dry }}\right] \cdot 100 \%$, $a_{\mathrm{w}}$ is the water activity (relative humidity/100), $h_{\mathrm{m}}$ is the percentage of water content directly bound to the hydrophilic sites, $c$ is the ratio of the binding constants of water molecule directly bound to the sorption site in the first layer and of that bonded indirectly in the succeeding liquid-like layers, and $f$ is the ratio of the standard chemical potential of the indirectly bound water molecule and that of the molecule in the bulk liquid state. The greater the value of $c$ is, the stronger the bond between the water molecule and the hydrophilic site, while low values of $f$ are indicative of hydrophobic character of polymer [37].

The values of the GAB equation parameters (shown on the graph of Figure 7) indicate the hydrophobic character of the sample (value of $f$ ) and the strong interaction of water molecules with its sorption sites (value of $c$ ). The values for the parameters of GAB equation are in accordance with those published in literature for epoxy resins [37]. No dependence of water sorption on sample composition was found as can be seen in Figure 8, where the sorption isotherms for all the systems studied are shown.

Kinetics of water vapor adsorption was studied and diffusion coefficient was calculated for different water contents from the measurements of the sample mass as a function of time at different levels of relative humidity. Experimental data for all the samples studied, independent of their composition, were well described by the one dimensional case of Fick's second law. The analysis was done as follows:

(i) By fitting the experimental data of mass as a function of time by the Equation (2):

$$
\begin{aligned}
m_{\mathrm{t}}= & m_{\mathrm{t}=0}+\left(m_{\mathrm{t}=\infty}-m_{\mathrm{t}=0}\right) \cdot \\
& \cdot\left[1-\exp \left[-7.3\left(\frac{D \cdot t}{l^{2}}\right)^{0.73}\right]\right]
\end{aligned}
$$

where $m_{\mathrm{t}}$ is the sample mass at each time $t, l$ is the thickness of the sample and $m_{\mathrm{t}=0}$ and $m_{\mathrm{t}=\infty}$ are the initial and the equilibrium mass, respectively and $D$ is the diffusion coefficient [37].

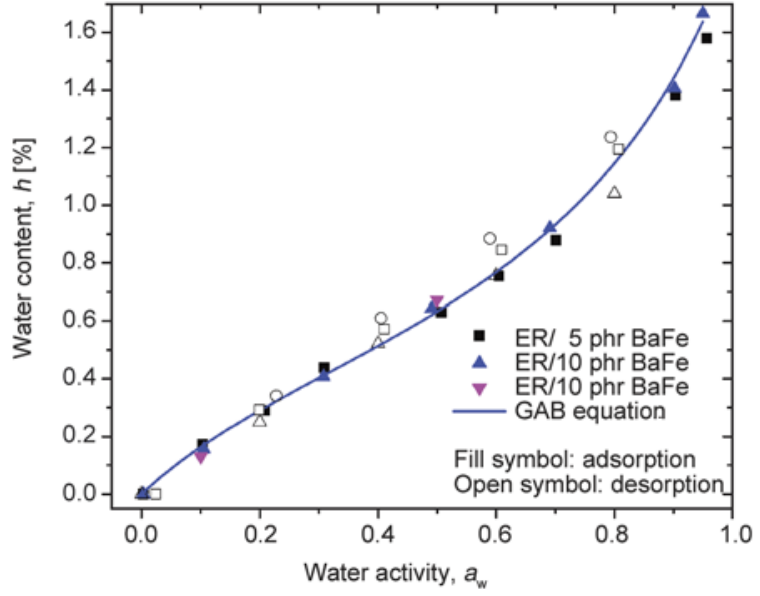

Figure 8. Water content as a function of water activity during adsorption (full symbols) and desorption (open symbols), for the nanocomposites indicated on the plot. The line is the best fit of GAB equation to the experimental data of the $10 \mathrm{phr}$ $\mathrm{BaFe}_{12} \mathrm{O}_{19}$ /epoxy nanocomposite.

(ii) By plotting the data of $\left(m_{\mathrm{t}}-m_{\mathrm{t}=0}\right) /\left(m_{\mathrm{t}=\infty}-m_{\mathrm{t}=0}\right)$ as a function of $\sqrt{t}$ and calculated diffusion coefficient from Equation (3):

$$
D=\operatorname{slope}^{2} \cdot \frac{l^{2} \cdot \pi^{2}}{16}
$$

where slope is the initial slope (for $y$ values up to $0.6)$ and $l$ is the thickness of the sample [37].

Similar values for the diffusion coefficient were calculated by both ways of fitting described above. The values of diffusion coefficient obtained from the experimental data of sorption as well as of desorption are presented in Figure 9 for all the samples

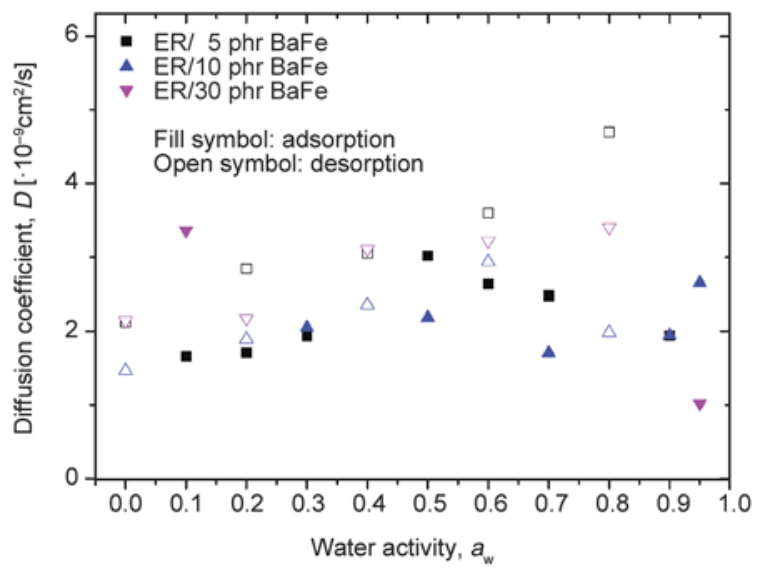

Figure 9. Diffusion coefficient values calculated from experimental data taken during adsorption (full symbols) and desorption (open symbols) as a function of water activity for the nanocomposites indicated on the plot 
under investigation. During adsorption a scattering of the data around the value of $2 \cdot 10^{-9} \mathrm{~cm}^{2} / \mathrm{s}$ independent of the sample composition and water activity (water content) was found, while during desorption diffusion coefficient values decrease with decreasing water activity (water content).

The hydrophobic character of the studied materials could be proved beneficial in their service life, especially in outdoors applications and in environmental conditions with high humidity. The unaffected, by water adsorption, polymer matrix will act as a protective shield for the reinforcing inclusions and thus their magneto-electric performance will not be disturbed.

\section{Conclusions}

In the present study composite systems of epoxy resin and barium ferrite nanoparticles have been prepared, and studied varying the content of the inclusions. The recorded dielectric relaxations are related to both the polymer matrix and the presence of the reinforcing phase. Dielectric permittivity and loss are increasing with filler and temperature. Effect of temperature is more pronounced in the low frequency range. Permittivity values diminish rapidly with frequency, reflecting the polarization vanishing, since permanent and induced dipoles fail to follow the alternation of the applied electric field. From the magnetization curves the coercive field decreases to $1.3 \mathrm{kOe}$ due to the presence of $\mathrm{Fe}_{2} \mathrm{O}_{3}$ in the powder. The saturation magnetization of nanocomposites decreases with decreasing of magnetic powder content.

Independent on their composition the nanocomposites absorb a small amount of water (percentage of water content at the highest water activity equal to $1.7 \mathrm{wt} \%$ ), indicating their hydrophobic character, while the adsorbed water do not cause permanent changes in the sample, which both are of great importance for their service life.

\section{Acknowledgements}

This research has been co-financed by the European Union (European Social Fund - ESF) and Greek national funds through the Operational Program 'Education and Lifelong Learning' of the National Strategic Reference Framework (NSRF) - Research Funding Program: THALES, MIS 379346 Investing in knowledge society through the European Social Fund.

\section{References}

[1] Walz F., Rivas J., Martínez D., Kronmüller H.: Influence of Ba content on the magnetic after-effect spectra in barium ferrites. Physica Status Solidi (a), 143, 137148 (1994). DOI: $10.1002 /$ pssa.2211430118

[2] Shi S., Yang Y., Xu J., Li L., Zhang X., Hu G-H., Dang Z-M.: Structural, optical and magnetic properties of co-doped $\mathrm{ZnO}$ nanorods prepared by hydrothermal method. Journal of Alloys and Compounds, 576, 5965 (2013). DOI: 10.1016/j.jallcom.2013.04.011

[3] Zhang L., Zhou P., Zhang H., Lu L., Zhang G., Chen H., Lu H., Xie J., Deng L.: A broadband radar absorber based on perforated magnetic polymer composites embedded with FSS. IEEE Transactions on Magnetics, 50, 4004305/1-4004305/5 (2014).

DOI: 10.1109/TMAG.2013.2293129

[4] Dong C., Wang X., Zhou P., Liu T., Xie J., Deng L.: Microwave magnetic and absorption properties of $\mathrm{M}$ type ferrite $\mathrm{BaCo}_{\mathrm{x}} \mathrm{Ti}_{\mathrm{X}} \mathrm{Fe}_{12-2 \mathrm{x}} \mathrm{O}_{19}$ in the Ka band. Journal of Magnetism and Magnetic Materials, 354, 340344 (2014).

DOI: 10.1016/j.jmmm.2013.11.008

[5] Huang X., Zhang J., Xiao S., Sang T., Chen G.: Unique electromagnetic properties of the zinc ferrite nanofiber. Materials Letters, 124, 126-128 (2014).

DOI: $10.1016 /$ j.matlet.2014.03.049

[6] Huang X., Zhang J., Xiao S., Chen G.: The cobalt zinc spinel ferrite nanofiber: Lightweight and efficient microwave absorber. Journal of the American Ceramic Society, 97, 1363-1366 (2014).

DOI: $10.1111 /$ jace. 12909

[7] Huang X., Zhang J., Liu Z., Sang T., Song B., Zhu H., Wong C.: Facile preparation and microwave absorption properties of porous hollow $\mathrm{BaFe}_{12} \mathrm{O}_{19} / \mathrm{CoFe}_{2} \mathrm{O}_{4}$ composite microrods. Journal of Alloys and Compounds, 648, 1072-1075 (2015).

DOI: $10.1016 /$ j.jallcom.2015.07.073

[8] Huang X., Chen Y., Yu J., Zhang J., Sang T., Tao G., Zhu H.: Fabrication and electromagnetic loss properties of $\mathrm{Fe}_{3} \mathrm{O}_{4}$ nanofibers. Journal of Materials Science: Materials in Electronics, 26, 3474-3478 (2015).

DOI: $10.1007 / \mathrm{s} 10854-015-2857-\mathrm{y}$

[9] Tan Y., Tang J., Deng A., Wu Q., Zhang T., Li H.: Magnetic properties and microwave absorption properties of chlorosulfonated polyethylene matrices containing graphite and carbonyl-iron powder. Journal of Magnetism and Magnetic Materials, 326, 41-44 (2013). DOI: $10.1016 /$ j.jmmm.2012.08.021

[10] Song Z., Xie J., Zhou P., Wang X., Liu T., Deng L.: Toughened polymer composites with flake carbonyl iron powders and their electromagnetic/absorption properties. Journal of Alloys and Compounds, 551, 677-681 (2013).

DOI: $10.1016 /$ j.jallcom.2012.11.065 
[11] Sim B., Chae H. S., Choi H. J.: Fabrication of polyaniline coated iron oxide hybrid particles and their dual stimuli-response under electric and magnetic fields. Express Polymer Letters, 9, 736-743 (2015). DOI: $10.3144 /$ expresspolymlett.2015.68

[12] Ren L., Zhao J., Wang S-J., Han B-Z, Dang Z-M.: Dielectric and magnetic properties of $\mathrm{Fe} @ \mathrm{Fe}_{\mathrm{x}} \mathrm{O}_{\mathrm{y}} /$ epoxy resin nanocomposites as high-performance electromagnetic insulating materials. Composites Science and Technology, 114, 57-63 (2015). DOI: $10.1016 /$ j.compscitech.2015.04.003

[13] Ren L., Zhao J., Wang S-J., Zha J-W., Hu G-H., Dang Z-M.: Remarkably variable dielectric and magnetic properties of poly(vinylidene fluoride) nanocomposite films with triple-layer structure. Composites Science and Technology, 107, 107-112 (2015). DOI: 10.1016/j.compscitech.2014.12.008

[14] Raptis C. G., Patsidis A., Psarras G. C.: Electrical response and functionality of polymer matrix-titanium carbide composites. Express Polymer Letters, 4, 234 243 (2010).

DOI: $10.3144 /$ expresspolymlett.2010.30

[15] Vavouliotis A., Fiamegou E., Karapappas P., Psarras G. C., Kostopoulos V.: DC and AC conductivity in epoxy resin/multiwall carbon nanotubes percolative system. Polymer Composites, 31, 1874-1880 (2010).

DOI: $10.1002 / p c .20981$

[16] Frickel N., Greenbaum A. G., Gottlieb M., Schmidt A. M.: Magnetic properties and dielectrical relaxation dynamics in $\mathrm{CoFe}_{2} \mathrm{O}_{4} @$ PU nanocomposites. The Journal of Physical Chemistry C, 115, 10946-10954 (2011). DOI: 10.1021/jp111348e

[17] Yang W., Yu S., Luo S., Sun R., Liao W-H., Wong CP.: A systematic study on electrical properties of the $\mathrm{BaTiO}_{3}$-epoxy composite with different sized $\mathrm{BaTiO}_{3}$ as fillers. Journal of Alloys and Compounds, 620, 315323 (2015).

DOI: 10.1016/j.jallcom.2014.09.142

[18] Psarras G. C.: Charge transport properties in carbon black/polymer composites. Journal of Polymer Science Part B: Polymer Physics, 45, 2535-2545 (2007). DOI: $10.1002 /$ polb.21278

[19] Toner V., Polizos G., Manias E., Randall C. A.: Epoxybased nanocomposites for electrical energy storage. I: effects of montmorillonite and barium titanate nanofillers. Journal of Applied Physics, 108, 074116/1074116/14 (2010).

DOI: $10.1063 / 1.3487275$

[20] Asimakopoulos I. A., Psarras G. C., Zoumpoulakis L.: Barium titanate/polyester resin nanocomposites: Development, structure-properties relationship and energy storage capability. Express Polymer Letters, 8, 692707 (2014).

DOI: $10.3144 /$ expresspolymlett.2014.72
[21] Tomara G. N., Kerasidou A. P., Patsidis A. C., Karahaliou P. K., Psarras, G. C., Georga S. N., Krontiras C. A.: Dielectric response and energy storage efficiency of low content $\mathrm{TiO}_{2}$-polymer matrix nanocomposites. Composites Part A: Applied Science and Manufacturing, 71, 204-211 (2015).

DOI: 10.1016/j.compositesa.2015.01.017

[22] Mathioudakis G. N., Patsidis A. C., Psarras G. C.: Dynamic electrical thermal analysis on zinc oxide/epoxy resin nanodielectrics. Journal of Thermal Analysis and Calorimetry, 116, 27-33 (2014).

DOI: $10.1007 / \mathrm{s} 10973-013-3510-8$

[23] Maliakal A., Katz H., Cotts P. M., Subramoney S., Mirau P.: Inorganic oxide core, polymer shell nanocomposite as a high $K$ gate dielectric for flexible electronics applications. Journal of the American Chemical Society, 127, 14655-14662 (2005).

DOI: $10.1021 / \mathrm{ja} 052035 \mathrm{a}$

[24] Iijima M., Sato N., Lenggoro I. W., Kamiya H.: Surface modification of $\mathrm{BaTiO}_{3}$ particles by silane coupling agents in different solvents and their effect on dielectric properties of $\mathrm{BaTiO}_{3}$ /epoxy composites. Colloids and Surfaces A: Physicochemical and Engineering Aspects, 352, 88-93 (2009).

DOI: 10.1016/j.colsurfa.2009.10.005

[25] Xie L., Huang X., Wu C., Jiang P.: Core-shell structured poly(methyl methacrylate) $/ \mathrm{BaTiO}_{3}$ nanocomposites prepared by in situ atom transfer radical polymerization: A route to high dielectric constant materials with the inherent low loss of the base polymer. Journal of Materials Chemistry, 21, 5897-5906 (2011).

DOI: $10.1039 / \mathrm{c} 0 \mathrm{jm} 04574 \mathrm{~h}$

[26] Zhang X., Chen H., Ma Y., Zhao C., Yang W.: Preparation and dielectric properties of core-shell structural composites of poly $(1 \mathrm{H}, 1 \mathrm{H}, 2 \mathrm{H}, 2 \mathrm{H}$-perfluorooctyl methacrylate)@BaTiO 3 nanoparticles. Applied Surface Science, 277, 121-127 (2013). DOI: $10.1016 /$ j.apsusc.2013.03.178

[27] Zhang X., Ma Y., Zhao C., Yang W.: High dielectric constant and low dielectric loss hybrid nanocomposites fabricated with ferroelectric polymer matrix and $\mathrm{BaTiO}_{3}$ nanofibers modified with perfluoroalkylsilane. Applied Surface Science, 305, 531-538 (2014). DOI: $10.1016 /$ j.apsusc.2014.03.131

[28] Tantis I., Psarras G. C., Tasis D.: Functionalized graphene - poly(vinyl alcohol) nanocomposites: Physical and dielectric properties. Express Polymer Letters, 6, 283292 (2012).

DOI: 10.3144/expresspolymlett.2012.31

[29] Dalle Vacche S., Leterrier Y., Michaud V., Damjanovic D., Månson J. A. E.: The influence of $\mathrm{BaTiO}_{3}$ surface modification on the dielectric and electromechanical properties of poly (vinylidene fluoride) copolymer composites. in 'Proceedings of the Fourth International Conference on Multifunctional, Hybrid and Nanomaterials' Sitges, Spain, P153 (2015). 
[30] Psarras G. C., Siengchin S., Karahaliou P. K., Georga S. N., Krontiras C. A., Karger-Kocsis J.: Dielectric relaxation phenomena and dynamics in polyoxymethylene/polyurethane/alumina hybrid nanocomposites. Polymer International, 60, 1715-1721 (2011).

DOI: 10.1002/pi.3136

[31] Pontikopoulos P. L., Psarras G. C.: Dynamic percolation and dielectric response in multiwall carbon nanotubes/poly(ethylene oxide) composites. Science of Advanced Materials, 5, 14-20 (2013).

DOI: $10.1166 /$ sam.2013.1425

[32] Singha S., Thomas M. J., Kulkarni A.: Complex permittivity characteristics of epoxy nanocomposites at low frequencies. IEEE Transactions on Dielectrics and Electrical Insulation, 17, 1249-1258 (2010).

DOI: $10.1109 /$ TDEI.2010.5539697

[33] Singha S., Thomas M. J.: Dielectric properties of epoxy nanocomposites. IEEE Transactions on Dielectrics and Electrical Insulation, 15, 12-23 (2008).

DOI: 10.1109/T-DEI.2008.4446732
[34] Patsidis A. C., Kalaitzidou K., Psarras G. C.: Dielectric response, functionality and energy storage in epoxy nanocomposites: Barium titanate vs exfoliated graphite nanoplatelets. Materials Chemistry and Physics, 135, 798-805 (2012).

DOI: $10.1016 /$ j.matchemphys.2012.05.060

[35] Chalashkanov N. M., Dodd S. J., Dissado L. A., Fothergill J. C.: Re-examination of the dielectric spectra of epoxy resins: Bulk charge transport and interfacial polarization peaks. IEEE Transactions on Dielectrics and Electrical Insulation, 21, 1330-1341 (2014). DOI: 10.1109/TDEI.2014.6832281

[36] Brunauer S., Deming L. S., Deming W. E., Teller E.: On a theory of the van der Waals adsorption of gases. Journal of the American Chemical Society, 62, 1723-1732 (1940). DOI: $10.1021 / \mathrm{ja} 01864 \mathrm{a} 025$

[37] Maggana C., Pissis P.: Water sorption and diffusion studies in an epoxy resin system. Journal of Polymer Science Part B: Polymer Physics, 37, 1165-1182 (1999). DOI: $10.1002 /($ SICI)1099-0488(19990601)37:11<1165 $\because$ AID-POLB11>3.0.CO;2-E 